\title{
Aprendizagem somática na formação em fisioterapia: processo educacional pela experiência do corpo
}

\author{
Somatic learning in Physical Therapy training: an educational process through body \\ experience
}

Somáticas en formación en terapia física: proceso educativo de la experiencia del cuerpo

Renata da Silva Peixoto ${ }^{*}$, Sheyla Costa Rodrigues².

\section{RESUMO}

Objetivo: $O$ estudo objetivou conhecer como 30 acadêmicos de um curso de Fisioterapia se percebem em relação as suas capacidades funcionais e como procedem quanto expostos a atividades que demandem exigências motoras. Método: Estudo realizado através da aplicação de um questionário aos discentes e uso de planilhas de observação estruturadas para acompanhamento das aulas práticas de Cinesiologia e Semiologia durante o período de 18 meses. Os dados foram analisados no programa Statistical Package for the Social Science (SPSS, versão 13.0; Inc., Chicago, IL, EUA). Resultados: O estudo mostrou comportamento distinto dos alunos na participação das atividades propostas nas aulas práticas do curso de Fisioterapia. Conclusão: Os colaboradores que auto relataram histórico de envolvimento em atividades práticas e percepção de habilidade em atividades com exigências motoras, mostraram atitude atuacionista em seu processo de formação, quando comparados a seus pares com pobre experiência procedimental e autopercepção de baixa habilidade em ações motoras.

Palavras-chave:Autopercepção, Experiência procedimental, Aprendizagem somática, Cognição incorporada.

\begin{abstract}
Objective: The study aimed to know how 30 academics of a Physiotherapy course, from a town of Rio Grande do Sul, perceive themselves in relation to their functional abilities and how they proceed when exposed to activities that demand motor requirements. Method: This study was carried out through the application of a questionnaire to the students and the use of observation worksheets structured to follow the practical classes of Kinesiology and Semiology during the period of 18 months. Statistical Package for the Social Science (SPSS, version 13:0; Inc., Chicago, IL, USA) analyzed data. Results: The study showed a different behavior in the students in their participation in the activities proposed in the practical classes of the Physical Therapy course. Conclusion: The collaborators who authorize a history of involvement in practical activities and perception of ability in activities with motor requirements, showed an active attitude in their process of training, when compared to their peers with poor procedural experience and self-perception of low ability in motor actions.
\end{abstract}

Keywords: Self-perception, Procedural experience, Somatic learning, Built-in cognition.

\footnotetext{
${ }^{1}$ Universidade Federal de Pelotas - UFPEL, Pelotas/RS, Professora Adjunta Substituta.

${ }^{*}$ E-mail: peixoto@vetorial.net

${ }^{2}$ Universidade Federal do Rio Grande - FURG, Rio Grande/RS, Professora Adjunta Associada.
}

SUBMETIDO EM: 11/2018

ACEITO EM: 12/2018

PUBLICADO EM: 01/2019 


\section{RESUMEN}

Objetivo: El estudio dirigido a conocer como 30 académicos de un curso de fisioterapia si darse cuenta acerca de sus capacidades funcionales y por qué como expuestos a actividades que requieren requisitos de motor. Método: Estudio mediante la aplicación de un cuestionario a los estudiantes y el uso de hojas de observación estructurada para acompañar las lecciones prácticas de Kinesiología y semiología durante el período de 18 meses. Los datos se analizaron en el programa paquete estadístico para las ciencias sociales (SPSS versión 13.0; Inc., Chicago, IL, Usa). Resultados: el estudio mostró distinguido comportamiento en los estudiantes en la participación en las actividades propuestas en las clases prácticas del curso de terapia física. Conclusión: los empleados que uno mismo historia de participación en actividades prácticas y la percepción de habilidad en actividades con requisitos motor, atuacionista demostró actitud en su proceso de formación, en comparación con sus pares con pobres experiencia procesal y autopercepción de habilidad baja en las acciones de motor.

Palabras-clave: Autopercepción, Experiencia procesal, Aprendizaje somático, Cognición encarnada.

\section{INTRODUÇÃO}

Compreender a formação profissional como possibilidade espaço-tempo, que permite ao estudante se aproximar das exigências de uma profissão, e de se entender continuamente em processo de transformação, ao promover o desenvolvimento das habilidades e competências inerentes a um campo profissional, nos permite compreender a exigência que as escolas de formação superior têm para propor ações pedagógicas que envolvam o discente, Ihe proporcionando capacitação teórico-prática que atenda às exigências de seu futuro campo profissional (MATURANA H e VARELA F, 2001).

A fisioterapia, por tratar-se de uma ciência que objetiva a prestação de serviços em saúde em níveis de atenção primário, secundário e terciário, e devido aos saberes que a compõem envolverem competências conceituais e procedurais necessita, em suas escolas de formação superior, a indispensável presença de laboratórios específicos para as práticas do curso. Esses espaços caracterizam-se por estrutura física que atentam o desenvolvimento e/ou aprimoramento de tais competências nos quais os discentes podem, através da exploração somática, promover a experiência corporal e atitudinal o mais próximo possível da realidade profissional da fisioterapia (WOLFE P, 2007).

As aulas práticas realizadas nos laboratórios têm por intenção promover experiências corporais que possam desenvolver os saberes do corpo que se dão no próprio processo do fazer, bem como, permitir compreender a ciência através de um corpo perceptual que se utiliza de suas sensações para dar sentido ao que experimenta (PEIXOTO R, 2014).

Ao compreender que aprendemos quando nos colocamos como sujeitos ativos no processo de formação, e que não existe um saber independente do sujeito que sabe, nos parece claro, que a possibilidade da transformação na formação, só se dará para os sujeitos da ação, que se percebem na ação, pois procedemos a partir do conceito que temos de nós mesmos. Nosso autoconceito está na dependência contínua de nosso sistema de alimentação sensorial (VARELA F et al., 2003). Esses autores afirmam que o nosso self não existe sem a atuação de nosso sistema perceptual. As experiências que vivemos são nossas fontes perceptuais permanentes. Dessa forma, quanto mais nos colocarmos em atitude atuacionista nos espaços de formação, nos permitindo viver o novo, mesmo que de novo, pois sempre será outra experiência, estaremos ampliando a possibilidade de lidar com novas informações sensoriais e assim, (re)construir nossas possibilidades de resposta.

Assim o laboratório, como espaço físico construído com características que facilitam a exploração somática; e as aulas práticas, vistas como momentos pedagógicos, assumem potencial para permitir experiência procedimental aliada à compreensão semântica dos conceitos discutidos pela ciência da 
reabilitação (PEIXOTO R, 2014). O presente artigo é resultado de uma investigação realizada durante as aulas práticas dos componentes curriculares Cinesiologia I e II e Semiologia Clínica Musculoesquelética I e II, junto aos discentes de um curso de Fisioterapia, e teve por objetivo conhecer como os acadêmicos se percebem em relação a suas capacidades funcionais e como procedem quanto expostos a atividades que demandem exigências corporais. As disciplinas Cinesiologia I e II têm por objetivo o desenvolvimento de saberes sobre como se dá o movimento humano e as disciplinas de Semiologia Clinica Musculoesquelética I e Il estudam o desenvolvimento de habilidades de avaliação cinético-funcionais.

\section{METODOLOGIA}

A pesquisa é composta de um estudo base que teve a participação de 100 acadêmicos e envolveu a aplicação de um questionário estruturado composto de questões fechadas, fazendo questionamentos sobre autopercepção funcional em relação às valências força, flexibilidade, agilidade e equilíbrio dinâmico. Os 100 alunos também foram avaliados fisicamente através de três testes físicos para obtenção de dados sobre as valências bimotoras: força de preensão palmar, elasticidade da cadeia posterior dos membros inferiores e agilidade e equilíbrio dinâmico (BERGAMO VR, et al., 2008).

Após a análise do questionário estruturado e dos testes físicos realizados com os 100 acadêmicos, foram selecionados 30 estudantes para dar seguimento ao estudo. A amostra foi intencional e não probabilística, baseada nas preocupações éticas e metodológicas discutidas nas Diretrizes e Normas Regulamentadoras da Pesquisa Envolvendo Seres Humanos (Resolução 466/2012).

A pesquisa transcorreu durante o período de três semestres letivos (segundo semestre de 2015 e primeiro e segundo de 2016), nos quais os alunos deveriam estar regularmente matriculados nas componentes curriculares citadas. Além disso deveriam ter frequência igual ou superior a $80 \%$ nas aulas práticas e não apresentar diagnóstico de patologia neurológica ou osteomuscular que comprometesse suas participações nas propostas práticas docentes.

Durante o período de 18 meses, os 30 alunos foram acompanhados nas disciplinas e suas ações em aula foram avaliadas pela frequência que se manifestavam a partir de uma planilha estruturada, que continha 9 critérios a serem observados: "mantém-se atento ás orientações do professor"; "executa o solicitado pelo professor"; "mostra dedicação para aprender a habilidade ensinada"; "pratica a habilidade motora com os colegas"; "demonstra habilidade motora ao praticar o movimento"; "preocupa-se com a qualidade da execução dos seus movimentos"; "expressa conexão da prática com a teoria já apresentada"; "identifica e autocorrige seus erros funcionais" e, "mostra evolução da habilidade motora com a experiência da prática".

As observações consideravam as respostas dos alunos frente às atividades propostas, e cada critério, classificado por frequência durante as aulas práticas, era sinalizado como: "sim", "não" e "ás vezes". A planilha de cada aluno também apresentava um espaço para observações complementares.

Os 30 selecionados foram divididos em 02 grupos de 15 participantes titulados "grupos A e B". O "grupo A" era composto pelos colaboradores com melhor score nos testes físicos e autoconceito de boa funcionalidade, e continha 08 membros do sexo masculino e 07 do sexo feminino. O "grupo B" foi composto pelos colaboradores com menor score nos testes físicos e autoconceito de menor capacidade funcional e foi composto exclusivamente por colaboradores do sexo feminino.

A pesquisa foi autorizada pelo Comitê de Ética em Pesquisa na área da Saúde da Universidade Federal do Rio Grande - FURG, sob o número 170/15, e pela direção da faculdade em que a mesma foi desenvolvida.

\section{ANÁLISE DOS RESULTADOS}

Dos 100 colabores, 30 estudantes foram selecionados para dar seguimento ao estudo, sendo 15 acadêmicos que apresentaram respostas limitantes em relação as suas capacidades funcionais e baixo score 
nos testes físicos e os outros 15 mostraram respostas confiantes em relação as suas capacidades funcionais e obtiveram maior score nos testes físicos. Participaram dessa fase do estudo 22 mulheres e 8 homens com idades que variavam dos 18 aos 38 anos.

Como o objetivo do estudo era compreender como os acadêmicos se percebem em relação a suas capacidades funcionais e como procedem quanto expostos a atividades que demandem exigências corporais, foi necessário conhecer suas percepções acerca de suas habilidades motoras nas etapas infância e adolescência e se, na atualidade, realizam a prática de alguma atividade motriz. Ao analisarmos suas respostas, identificamos uma divergência entre os grupos $A$ e $B$, como mostra a Tabela 1.

Tabela 1 - Práticas físicas.

\begin{tabular}{lcc}
\hline & Grupo A & Grupo B \\
\hline Atividade Física & $12(80 \%)$ & $02(13 \%)$ \\
Sim & $03(20 \%)$ & $13(87 \%)$ \\
Não & & \\
Habilidades Motoras na Infância e Adolescência & $04(27 \%)$ & $01(7 \%)$ \\
Facilidade para realizar os movimentos, com destaque & $11(73 \%)$ & $11(73 \%)$ \\
Realizava os movimentos, mas sem destaque & $0(0 \%)$ & $02(13 \%)$ \\
Nem sempre conseguia fazer movimentos & $0(0 \%)$ & $01(7 \%)$ \\
Sem aptidão para atividades motoras & & \\
\hline
\end{tabular}

Fonte: Dados da pesquisa, 2018.

A seguir, o Gráfico 1 mostra a existência de habilidade motora por parte dos alunos na realização das atividades práticas propostas nas aulas, sendo habilidade definida como a capacidade de realizar um ato motor, de forma fluída, com mínimo esforço na execução, demonstrando direção, velocidade e nível de tensão muscular adequado na ação.

Gráfico 1 - Habilidade no movimento.

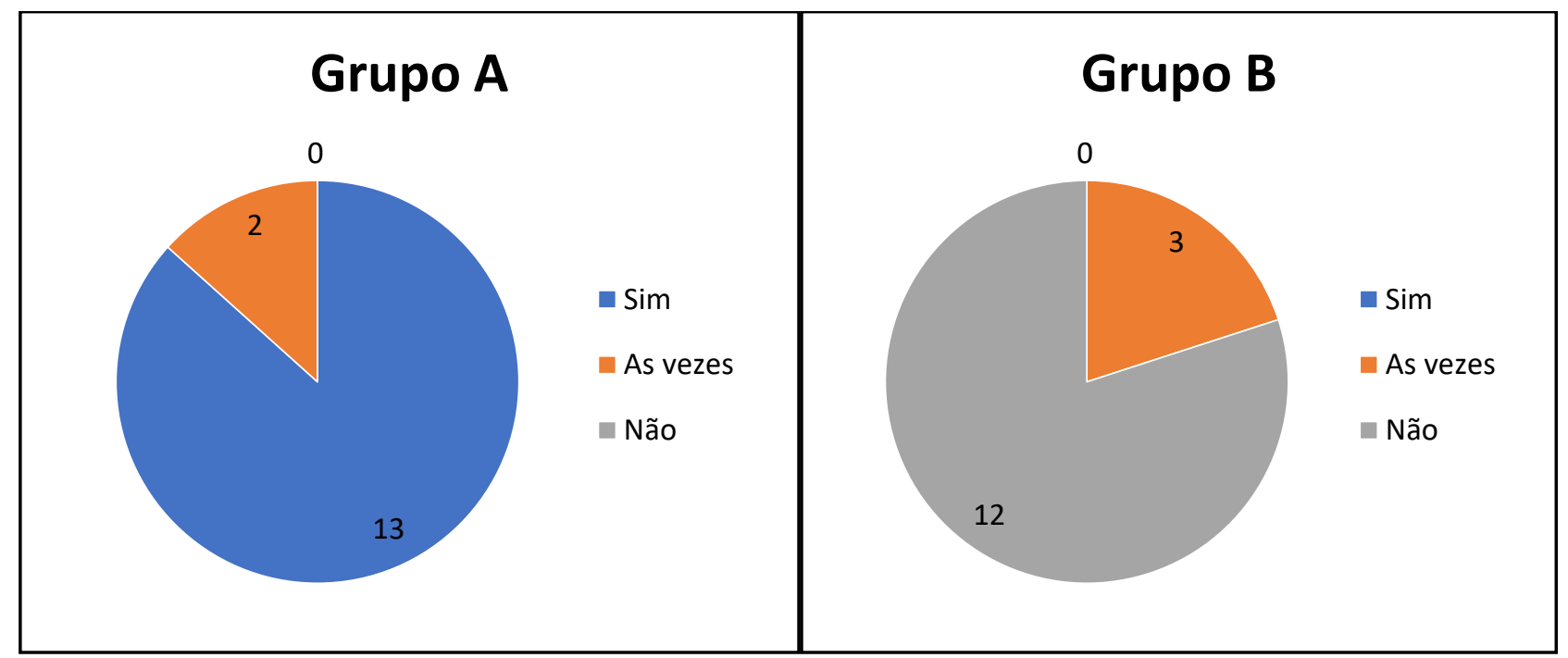

Fonte: Dados da pesquisa, 2018.

Para Maturana H e Varela F (2001), a aprendizagem é consequência da história individual de todo ser vivo com plasticidade estrutural ontogênica. Por isso, torna-se necessário investigar como os acadêmicos se percebem em relação a sua capacidade para aprender atos motores terapêuticos durante o curso, bem como sua atitude para a realização dos movimentos ensinados nas atividades propostas durante a aula. Analisando as fichas de observação identificamos os seguintes resultados (Tabela 2). 
Para que as estratégias pedagógicas desenvolvidas pelos docentes, alcancem seus objetivos é essencial que os alunos colaborem e participem das propostas. Durante os 18 meses do estudo nosso objetivo foi identificar o interesse e a dedicação dos alunos para aprender os movimentos terapêuticos nas aulas práticas das componentes curriculares pesquisadas (Gráfico 2).

Tabela 2 - Aprendizagem e apresentação de movimento terapêutico,

\begin{tabular}{lcc}
\hline & Grupo A & Grupo B \\
\hline Aprendizagem do movimento & & \\
Ocorre de forma rápida & $08(53 \%)$ & $0(0 \%)$ \\
Necessito praticar & $07(47 \%)$ & $13(87 \%)$ \\
Tenho dificuldade & $0(0 \%)$ & $02(13 \%)$ \\
Realização do movimento & & \\
Sim, aprenderei ao fazer & $10(67 \%)$ & $05(33 \%)$ \\
Sim, mas só após praticar & $05(33 \%)$ & $01(7 \%)$ \\
Não, só observarei & $0(0 \%)$ & $09(60 \%)$
\end{tabular}

Fonte: Dados da pesquisa, 2018.

Gráfico 2 - Dedicação na aprendizagem dos atos motores terapêuticos.

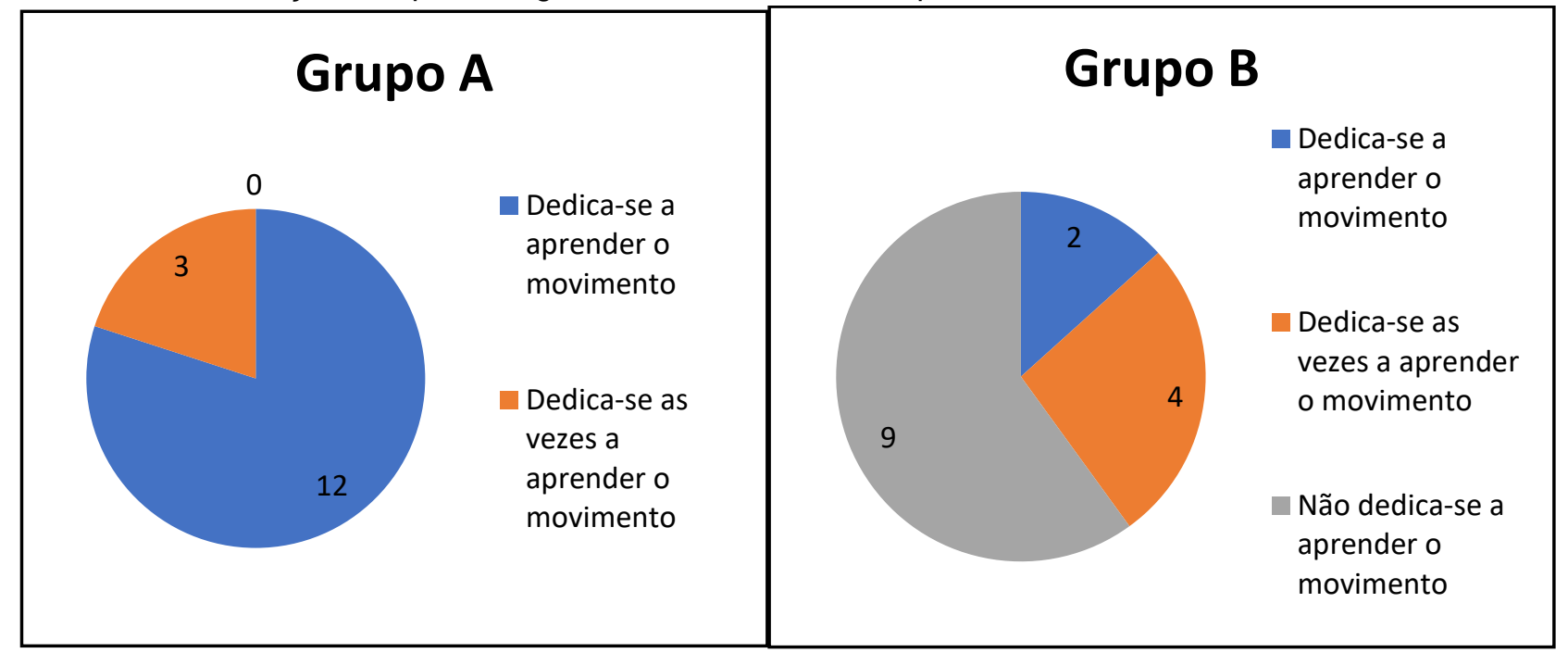

Fonte: Dados da pesquisa, 2018.

Para Darido S e Rangel I (2011), saberes são conhecimentos, competências, habilidades e atitudes que são conquistadas no processo da experiência, por isso faz-se necessária a participação e a convivência dos alunos com seus professores e seus pares. As relações produzidas nessas interações são um fomento para o desenvolvimento de diferentes saberes por parte dos acadêmicos. Negar a convivência e a experiência provindas da participação atuacionista nas práticas propostas nas escolas de formação superior, limita 0 desenvolvimento de saberes experienciais, que se constituem de memórias marcantes, que englobam aspectos afetivos e interpessoais.

O Gráfico 3 mostra o comportamento dos alunos na interação com seus colegas na experimentação das práticas terapêuticas, bem como o reconhecimento de seus pares como sujeitos da convivência para a produção e compartilhamento de saberes. 
Gráfico 3 - Prática dos movimentos terapêuticos com seus colegas.

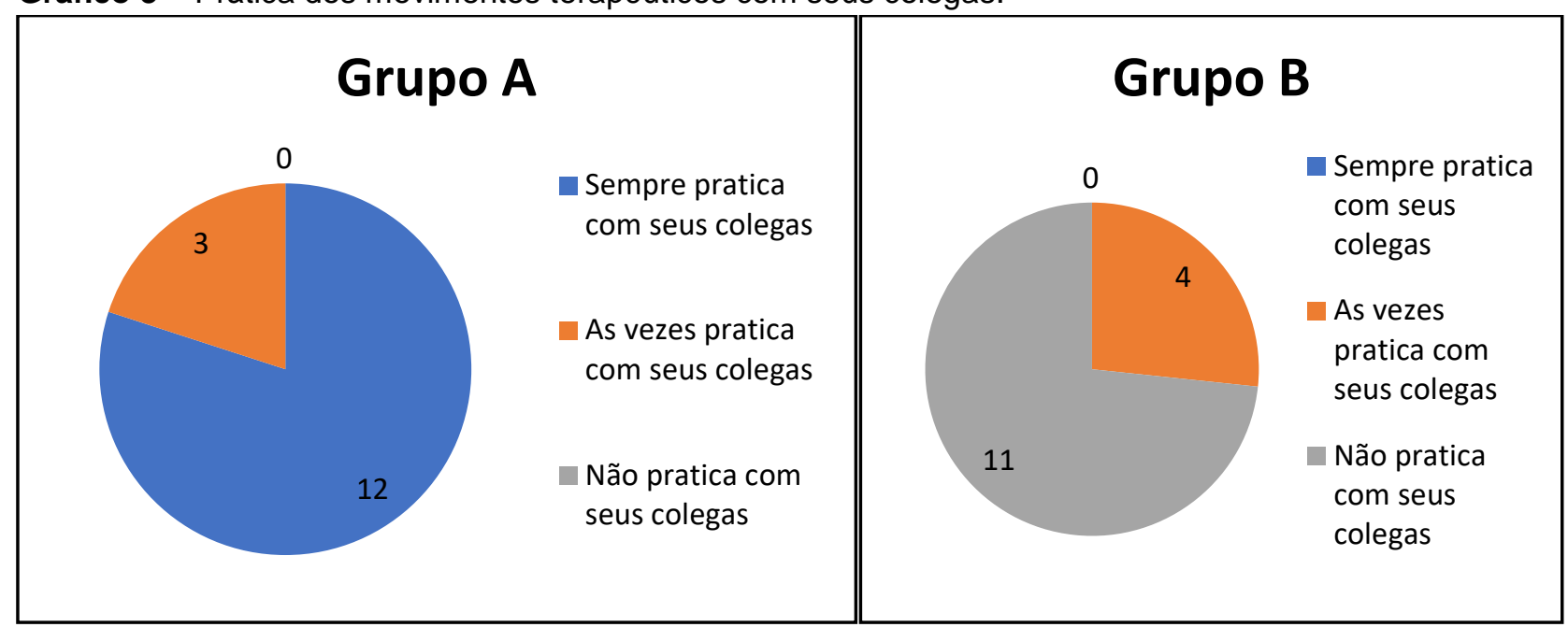

Fonte: Dados da pesquisa, 2018.

\section{DISCUSSÃO}

Não é incomum encontrarmos em cursos superiores como Educação Física e Fisioterapia, acadêmicos com amplas vivências em atividades físicas e esportes. O gosto por essas práticas, que envolvem o corpo, bem como, exploram suas capacidades, muitas vezes, acabam por despertar nos praticantes, interesse em compreender como se dá o desenvolvimento das habilidades motoras, bem como potencializá-las (DARIDO S e RANGEL I, 2011).

Mas, por mais que esses sujeitos fisicamente ativos sejam encontrados nas escolas, que têm por intenção à capacitação científica em saberes do corpo e suas competências motoras, também encontramos estudantes não envolvidos em práticas, que facilitam o conhecer do corpo pelo corpo, com um histórico empobrecido de vivências somáticas, possibilitadas pelas práticas físicas e dos esportes (PEIXOTO R, 2014).

Em relação ao questionamento sobre a realização atual de práticas físicas, identificamos diferença entre os grupos, com $80 \%$ dos participantes do "grupo A", participando de atividades que envolvem exigências motoras, enquanto $87 \%$ dos participantes do "grupo B", não estão envolvidos em atividades com exigências físicas. Esses dados podem justificar os scores dos testes físicos que foram usados como critério de seleção para a composição dos grupos. Os integrantes do "grupo A" apresentam bons resultados nos testes físicos e os do "grupo B" indicam baixos resultados nos testes físicos.

A realização de atividades de ordem motora garante o desenvolvimento de elementos estruturais somáticos como os grupamentos musculares, matriz óssea, estruturas articulares, tecidos periarticulares, bem como a ativação do sistema nervoso para lidar com as informações perceptuais e a programação da resposta motriz. Estes, ao serem recrutados na realização das práticas, potencializam a reconfiguração dessas estruturas e dessa forma, permitem a maximização fisiológica de seus componentes (COTRIM JR, 2011).

Competências motoras, esperadas em determinados momentos do desenvolvimento motor natural dos sujeitos, dependem de elementos multicausais, que vem desde as características inatas de cada humano, bem como, à exposição a ambientes motivacionais, que atentem à possibilidade de exploração corporal para gerar autoconhecimento das capacidades funcionais reais, bem como, as valências bimotoras que necessitam ser alcançadas (CLARK JE, 2007).

Não é incomum observamos comportamento motor autoinibido por parte de sujeitos que obtiveram experiências motoras na infância e/ou adolescência com baixo desempenho funcional. Muitas vezes, a autoprivação da experimentação procedural pode ocorrer devido a esses sujeitos não terem sido expostos á práticas físicas devidamente pensadas e planejadas, considerando o momento motor e o nível de habilidade motriz em que se encontravam (BRAGA RK et al. 2009; VALENTINI NC 2002). Estudos mostram que 0 
desenvolvimento natural de habilidades motoras fundamentais na primeira década de vida sem a necessidade de interferência educacional sistemática perdeu espaço (GALLAHUE DL e DONNELLY FC, 2008). As pesquisas de Cotrim JR et al. (2011); Lemos AG et al. (2012); Pang AMY e Fong DTP (2009), têm indicado que crianças podem não alcançar níveis mais elevados de desempenho motor em suas habilidades fundamentais, quando privadas de oportunidades de conviver com práticas sistematizadas, que permitam experiências diversificadas, com exigências físicas variadas e adequadas a cada momento motor.

Barreiras na proficiência motora podem ser apontadas como uma das causas da não participação dos acadêmicos às propostas pedagógicas promovidas nas aulas práticas (CLARK JE, 2007 e GALLAHUE DL e DONNELLY FC, 2008). Histórico de bom desempenho em atividades com exigências motoras por parte dos estudantes, pode ser o elemento facilitador de seus envolvimentos nas atividades acadêmicas práticas em seus processos de formação profissional.

O resultado das observações realizadas nas aulas práticas das disciplinas apontadas no estudo, mostra que 13 colaboradores (87\%), pertencentes ao "grupo A", ao realizarem os movimentos propostos nas atividades acadêmicas da aula, sempre demonstraram habilidade motora na execução dos exercícios, realizando as propostas com fluidez coordenativa cinética, evidenciando facilidade, tanto na compreensão das etapas dos gestos motores, bem como, nas exigências corporais para um bom desempenho funcional. Se a experiência procedural reconfigura os agentes efetores durante o processo exigido na atividade, os modulando e os transformando, as memórias oriundas de atividades motoras executadas com qualidade gestual, permitem reconfiguração somática e mnemônica satisfatórias (LACOURSE MG, 2004).

No gesto motor, demonstração de habilidade é indicativo de qualidade, assim, na experiência do movimento da maioria dos componentes do "grupo A" (87\%), memórias positivas foram produzidas nessas ações, e essas, são as marcas que a formação formal deseja produzir no aluno.

No "grupo B", apenas $2(20 \%)$ colaboradores, demonstraram habilidade motora em suas participações em algumas atividades propostas, e em raros momentos das aulas, os alunos se dispuseram a participar de atividades práticas. O resultado de $12(80 \%)$ acadêmicos não apresentarem habilidade motora ao realizar as práticas terapêuticas na aula, pode ser indicador do desinteresse dos participantes do "grupo B" de participarem das propostas práticas. Esse desinteresse atual pelas práticas necessárias para 0 desenvolvimento dos saberes pertinentes às diferentes componentes curriculares analisadas, pode ser uma consequência da inabilidade ou da falta de exigências físicas variadas e adequadas a cada momento motor.

O envolvimento dos sujeitos em atividades físicas é uma ação que permite desenvolver prazer através do movimento (MORANO M et al., 2011). No processo da experiência, e no que se refere às competências motoras, os praticantes de atividades físicas mantêm e/ou desenvolvem competências somáticas necessárias para a aprendizagem de saberes indispensáveis à formação em Fisioterapia.

Hoje, ao considerarmos a realização de atividades físicas, chama a atenção, o indicativo de relação entre essas práticas e o desenvolvimento de competências motoras. No "grupo A", temos $80 \%$ dos componentes ativos (Tabela 1), com $87 \%$ deles (Gráfico 1) sempre demonstrando habilidade motora nas aulas práticas do curso. No "grupo B", $87 \%$ dos componentes (Tabela 1) afirmam serem inativos, com $80 \%$ deles (Gráfico 1) não demonstrando, em nenhuma prática acadêmica, habilidade motora na execução das atividades. Esses resultados mostram a importância da experiência procedimental para o desenvolvimento de habilidades motrizes.

O resultado ao questionamento sobre a percepção dos colaboradores do "grupo A" sobre suas capacidades de aprender atos motores terapêuticos, objetivo das componentes curriculares, nas quais foi desenvolvida a pesquisa, aponta confiança por parte dos integrantes, com mais de $50 \%$ dos integrantes do grupo (Tabela 2), identificando-se com facilidade de aprendizagem. Esses estudantes consideram que sua capacitação se dará de forma rápida e fluída em dissonância com os alunos do "grupo B" (Tabela 2), em que nenhum se identificou nessa caracterização.

Pela análise da Tabela 2 a grande maioria (87\%) dos estudantes do "grupo B", se percebe com potencial para aprender as estratégias terapêuticas cinéticas ensinadas, mas relatam que para que o processo de aprendizagem ocorra e realizem as propostas frente a seus colegas, necessitam de certo tempo de prática. 
Entretanto, quando questionados sobre a adesão para a realização dos movimentos terapêuticos nas aulas, $60 \%$ do grupo (Tabela 2), afirmam que assumem um comportamento de observador durante as aulas, resultado que vai de encontro as suas percepções de que o seu aprender motor depende de prática repetida da ação. É possível que a percepção de reduzida habilidade motora, e a crença de constrangimento à exposição frente a seus pares, seja oriunda de memórias de baixo êxito em atividades com exigências motoras.

Professores que conhecem as experiências de seus alunos e estão atentos as suas dificuldades, lacunas e limitações, podem desenvolver programas específicos de intervenção para o desenvolvimento de competências e habilidades de ordem motora (BRAUNER LM e VALENTINI NC, 2009), como é o caso das aulas práticas dos cursos de Fisioterapia, nas quais as intervenções pedagógicas visam ampliar o leque conceitual e procedimental dos alunos.

Quando questionamos a capacidade de aprendizagem de movimentos terapêuticos dos pesquisados (Tabela 2), vemos que todos os colaboradores do "grupo A", acreditam que apresentam competência para aprender os movimentos de forma rápida ou através de certo período de treinamento. Corroborando com essa afirmação, o Gráfico 2 aponta que 80\% dos colaboradores do "grupo A", mostram-se dedicados a aprender os movimentos terapêuticos trabalhados na sala de aula, enquanto que $20 \%$ indicam que, pelo menos em alguns momentos, apresentam esse comportamento ativo e de responsabilização pelo seu aprender.

A aprendizagem procedimental ocorre por meio de um papel atuacionista no processo educativo. Não há a possibilidade de desenvolver competências de ordem cinética sem ser sujeito ativo no aprender. É necessário que o aluno sempre se responsabilize por seu processo de transformação na educação.

Ao relacionarmos os resultados da Tabela 2 e do Gráfico 2, referentes ao "grupo B", identificamos incoerência entre o que os acadêmicos dizem de si, com o que foi observado nas práticas. Por mais que 13 colaboradores $(87 \%)$ do "grupo B" (Tabela 2), relatem que suas aprendizagens de ordem motora acontecem após certo tempo de treinamento; ao serem observados no laboratório de aulas práticas, 9 alunos $(60 \%)$ do "grupo B" conforme o Gráfico 2 assumem a postura de desinteresse em aprender os gestos terapêuticos ensinados nas aulas, 4 ou $27 \%$ mostram interesse em algumas práticas para aprender os movimentos e apenas 2 alunos (13\%) evidenciam interesse em aprender os gestos terapêuticos propostos pela docente de forma espontânea.

A cognição, segundo Varela $\mathrm{F}$ et al. (2003) não é a representação de um mundo prévio por uma mente pré-existente e sim, a enação de um mundo e uma mente com base numa história de diversas ações realizadas pelo ser no mundo. Estar disponível para que algo nos aconteça e ser receptivo às manifestações sensoriais que emergem dos processos experienciais do viver e sentir, é uma ação necessária para que o sujeito que experimenta, promova a reformulação de suas respostas de forma enativa, e não a reprodução de respostas pré-estabelecidas, mas construídas pelo fazer e durante o fazer. Por isso, é indispensável a mobilização e o interesse pelas atividades práticas em um curso de formação profissional, em que os sujeitos precisam conhecer o próprio corpo para propor ações terapêuticas ao corpo do outro.

Os resultados do Gráfico 2 mostram que os acadêmicos do "grupo B", em sua maioria (60\%), ao não demonstrarem disponibilidade para aprender pelo fazer, privam-se da produção de outras e/ou novas respostas às percepções do seu corpo em ação, inibindo o emergir de saberes oriundos da experiência do corpo, limitando seus desenvolvimentos conceitual e procedimental, que são objetivos da formação em Fisioterapia. A maioria dos integrantes do "grupo A" (80\%) ao contrário mostra-se receptiva e disponível para desenvolver as competências de ordem motora através de suas próprias ações, se colocando em atitude ativa para aprender não apenas os conceitos trabalhados na estratégia terapêutica, mas o emergir de um saber enatuado, que se manifesta através do fazer consciente.

Ao considerarmos esses acadêmicos, em processo de formação profissional, emerge a preocupação com a conduta manifesta dos componentes do "grupo B", uma vez que 11 deles $(73 \%)$ não praticam os movimentos terapêuticos ensinados, assumindo uma atitude passiva, limitada a assistir seus colegas de turma a praticar os movimentos com seus pares, como mostra o Gráfico 3. O ensaio mental, que ocorre quando olhamos um 
ato motor, acontece se estivermos em atitude consciente, e por mais que os acadêmicos ativem as mesmas redes neurais, ao não vivenciarem as experiências geradas pelo corpo em experimentação procedimental, essa ativação se dará em menor intensidade (LACOURSE MG, 2004 e AMEMYA K, 2010).

O processo de observação, utilizado como instrumento no estudo, não nos permite afirmar se os 11 (73\%) alunos do "grupo B" (gráfico 3), que apenas olham os colegas realizarem os movimentos trabalhados nas aulas, encontram-se em processo de ensaio mental. Porém, podemos afirmar que, mesmo que estejam nessa ação mental, percepções sensoriais oriundas do corpo em atuação e a potencialização de todos os elementos somáticos recrutados nos atos motores não se darão se optarem por esse tipo de experiência na prática terapêutica (MULDER T et al., 2004). Quando se experiencia algo novo, o cérebro procura uma rede já existente, na qual a nova informação se ajustará, por isso, as sinapses neuronais são mais eficientes quanto mais vezes um padrão de comunicação interneuronal for ativado (WOLFE $P$, 2007).

O Gráfico 3, mostra que 12 (80\%) acadêmicos do "grupo A", se colocam em atitude ativa, realizando os movimentos terapêuticos trabalhados nas aulas com seus colegas, o que nos permite dizer que, as relações sociais ali estabelecidas, bem como as percepções sensoriais produzidas por seus corpos, otimizam suas aprendizagens, Ihes possibilitando incrementar os saberes experienciais. $O$ aluno que liga as novas informações sensoriais provindas de novas experiências, não só aumenta a complexidade das conexões neuronais, como também fortalece a retenção dessas informações (MULDER T et al., 2004). Entrelaçados em uma rede dinâmica, seus saberes estarão prontos a serem modificados e readaptados às novas informações provenientes de suas experiências (VARELA et al., 2003).

Flexibilidade cognitiva, promovida através de experiências motoras ocorrem pela contínua comunicação mente e corpo, e cabe a essa mente incorporada estabelecer a maior quantidade possível de ligações, para que novas coordenações de ações inter neuronais possam emergir das experiências vivenciadas. Reconhecer a existência de saberes de cunho motor por parte dos alunos e gerar oportunidades, através de estratégias pedagógicas, para que elas se revelem, permitem ao professor conhecer as competências, bem como as limitações funcionais de seus alunos, oportunizando ao docente adaptar suas aulas às possibilidades e necessidades dos discentes (DARIDO S e RANGEL I, 2011).

\section{CONCLUSÃO}

A construção de um referencial mnemônico procedural, bem como, o desenvolvimento de valências bimotoras, como equilíbrio, força, agilidade, flexibilidade e outras, produzidas pela experimentação motora das atividades práticas propostas nas situações de aprendizagem, permitirá que os alunos, quando expostos a outros contextos com exigências procedurais, possam estabelecer relação com essas experiências acadêmicas, ampliando e reconfigurando as redes neuronais já formadas. Ao se darem conta de que são transformados na convivência, emerge o sentido da incompletude e incertezas, que os levará a buscar cotidianamente o que Ihes falta e a desenvolver habilidades e capacidades de interpretação e improvisação, Ihes permitindo decidir a melhor estratégia diante de um evento qualquer e possibilitando criar outra emoção produzida pela experiência vivida, possibilitando assim, uma re(construção) cognitiva enatuada de si através de suas ações incorporadas.

\section{REFERÊNCIAS}

1. AMEMYA K. Effects of motor imagery on intermanual transfer: a near-infrared spectroscopy and behavioral study. Brain Research, 2010; 1343, 93-103.

2. BERGAMO VR, et al. Medida e Avaliação em Educação Física e Esportes. Campinas, 2008; 178p.

3. BRAGA RK, et al. A influência de um programa de intervenção motora no desempenho das habilidades locomotoras de crianças com idade entre 6 e 7 anos. Revista da Educação Física/UEM, 2009; 20(2), 171-181.

4. BRAUNER LM, VALENTINI NC. Análise do desempenho motor de crianças participantes de um programa de atividades físicas. Revista da Educação Física/UEM, 2009; 20(2), 205-216.

5. CLARK JE. On the problem of motor skill development. JOPERD, 2007; 78(5), 39-45. 
6. COTRIM JR, et al. Desenvolvimento de habilidades motoras fundamentais em crianças com diferentes contextos escolares. Revista de Educação Física/UEM, 2011; 22(4), 523-533.

7. DARIDO S, RANGEL I. Educação Física na escola: Implicações para a prática pedagógica. 2 ed. Rio de Janeiro: Guanabara Koogan, 2011; 316p.

8. GALLAHUE DL, DONNELLY FC. Educação Física Desenvolvimentista para Todas as Crianças. 4 ed. São Paulo, SP: Phorte, 2008; 725p.

9. LACOURSE MG. Cerebral and cerebellar sensoriomotor plasticity following motor imagery based mental practice of a sequential movement. Journal of rehabilitation research and development., 2004; 41(4), 505-524.

10. LEMOS AG, et al. Physical Education in kindergarten promotes fundamental motor skill development. Advances in Physical Education, 2012; 2(1), 17-21.

11. MATURANA H, VARELA F. A árvore do conhecimento: as bases biológicas da compreensão humana. São Paulo: Palas Athenas, 2001; 288p.

12. MORANO M, et al. Body image, perceived and actual physical habilities in normal-weight and overweight boy involved in individual and team sports. Journal of Sports Sciences, 2011; 29(4), 355-362.

13. MULDER T, et al. The role of motor imagery in learning a totally novel movement. Experimental Brain Research, 2004; 153, 211-217.

14. PANG AWY, FONG DTP. Fundamental motor skill proficiency of Hong Kong children aged 6-9 years. Research in Sports Medicine, 2009; 17(2), 125-144.

15. PEIXOTO R. O educador físico como mediador do habitus motriz: uma abordagem neuroeducacional. Dissertação (Mestrado em Educação em Ciências: Química da Vida e Saúde) - PPGEC: Universidade Federal do Rio Grande, Rio Grande, 2014, 147p.

16. VALENTINI NC. Percepções de competência e desenvolvimento motor de meninos e meninas: um estudo transversal. Movimento, 2002; 8(2), 51-62.

17. VARELA F, et al. A Mente corpórea: ciência cognitiva e experiência humana. Lisboa: Instituto Piaget, 2003; 294p.

18. WOLFE P. Compreender o funcionamento do cérebro e sua importância no processo de aprendizagem. Porto: Porto Editora, 2007; 192p. 